\title{
Identification and Characterization of High Permeability Zones Using Conventional Logging and Production Logging Data: A Case Study of Kela 2 Gas Field
}

\author{
Yongzhong ZHANG ${ }^{1}$, Hualin LIU, Weigang HUANG, Zhaolong LIU and Baohua \\ CHANG \\ PetroChina Research Institute of Petroleum Exploration \& Development, Beijing, \\ China
}

\begin{abstract}
High permeability zones in the water-drive gas reservoir tend to act as dominant channels for formation water to invade into gas reservoir from the aquifer. The presence of high permeability zones results in uneven water flow front in reservoir and early water breakthrough in gas well, which seriously affects the gas field development. In this paper, conventional logging and production logging data are used to identify and characterize high permeability zones, so as to guide the optimization of development plan of Kela 2 gas field. A method to determine the lower limit of high permeability zones by using cumulative frequency curve of permeability distribution is proposed, and high permeability zones of 21 wells are identified. These high permeability zones account for $10-15 \%$ of the effective reservoir thickness in single wells, and they are mainly distributed in the middle of the Bashijiqike $\left(\mathrm{K}_{1} b s\right)$ Formation (i.e., $\mathrm{K}_{1} b s_{1}{ }^{2}, \mathrm{~K}_{1} b s_{2}{ }^{1}$ and $\left.\mathrm{K}_{1} b s_{2}{ }^{2}\right)$. The analysis of production logging data shows that the effective gas producing intervals only account for $29.2 \%$ of the total number of test intervals, most of which are related to high permeability zones. Further study shows that the high gas flow from the high permeability zones dominates the wellbore production profile, and the gas in low permeability zones flows vertically to the high permeability zones and horizontally to wellbore through these zones. Through the analysis of production profiles over the years and computer modelling, it is confirmed that water channelling occurred in some gas wells at the depth where the high permeability zones are located, which leads to a significant decline in production of these wells. Based on the study of distribution and behaviour characteristics of the high permeability zones, two suggestions on controlling inhomogeneous water invasion are put forward to realize the sustainable and stable production of the gas field.
\end{abstract}

Keywords. Kela 2 gas field, high permeability zone, production logging, water invasion

\section{Introduction}

Reservoirs are often heterogeneous influenced by sedimentation and diagenesis [1-3]. There exist some zones with permeability much higher than the average permeability of

\footnotetext{
${ }^{1}$ Corresponding Author, Yongzhong ZHANG, PetroChina Research Institute of Petroleum Exploration \& Development, Beijing, China; Email: zhangyongzhong69@petrochina.com.cn.
} 
the target reservoir, which are called high permeability zones [4, 5]. Acting as rapid velocity flow conduits, the high permeability zones cause early water breakthrough in well [6], which seriously affects the gas field development. Geologists and reservoir engineers have studied high permeability, or main flow channels, with different perspectives. In previous studies, geological analysis, physical simulation experiment, and production logging are usually used to identify high permeability zones [7-10]; while production logging, reservoir engineering and numerical simulation are often used to describe the behaviour of high permeability zones, or main flow channels [11-15]. In this paper, taking Kela 2 gas field for an example, based on core and logging data analysis, combined with gas production profiles, high permeability zones are identified and their behaviours are interpreted, which provides guidance for the optimization of development plan of Kela 2 gas field.

\section{Geological Characteristics of Kela 2 Gas Field}

Kela 2 gas field, located in the Kelasu Structural Belt of Kuqa Depression, Tarim Basin, is the largest uncompartmentalized gas field in China. The main gas bearing formations include Palaeogene Glutenite $\left(\mathrm{E}_{1-2} \mathrm{~km}_{5}\right)$ and a large set of sandstones interbedded with siltstones and mudstones belonging to the Cretaceous Bashijiqike $\left(\mathrm{K}_{1} b s\right)$ and Baxigai $\left(\mathrm{K}_{1} b x\right)$ Formations, with a total thickness of about $450 \mathrm{~m}$ (figure 1), which were deposited in braided delta and fan delta environment [16]. The reservoirs are thick-very thickbedded sandstone, with more than $80 \% \mathrm{~N}$ : $\mathrm{G}$ (net to gross) ratio, and they are in communication with each other due to the presence of faults and fractures within the reservoirs $[17,18]$. The sandstone reservoirs are seriously heterogeneous. According to the analysis of 1715 core plug samples from 7 wells, the porosity varies from $0.76 \%$ to $22.39 \%$ (figure $2 \mathrm{a}$ ), with an average porosity of $12.44 \%$; the permeability varies from $0.008 \mathrm{md}$ to $1770.15 \mathrm{md}$ (figure $2 \mathrm{~b}$ ), with an average value of $49.42 \mathrm{md}$. There is a good correlation between porosity and permeability (figure 2c). Kela 2 gas field was put into development in 2004. With the rapid development, some wells have experienced early water breakthrough associated with high permeability matrix zones as well as faults and fractures. Researchers pay more attention to the study of fault or fracture characteristics [17-19], but less on the description of high permeability matrix. This paper would focus on characterization of the high permeability matrix. 


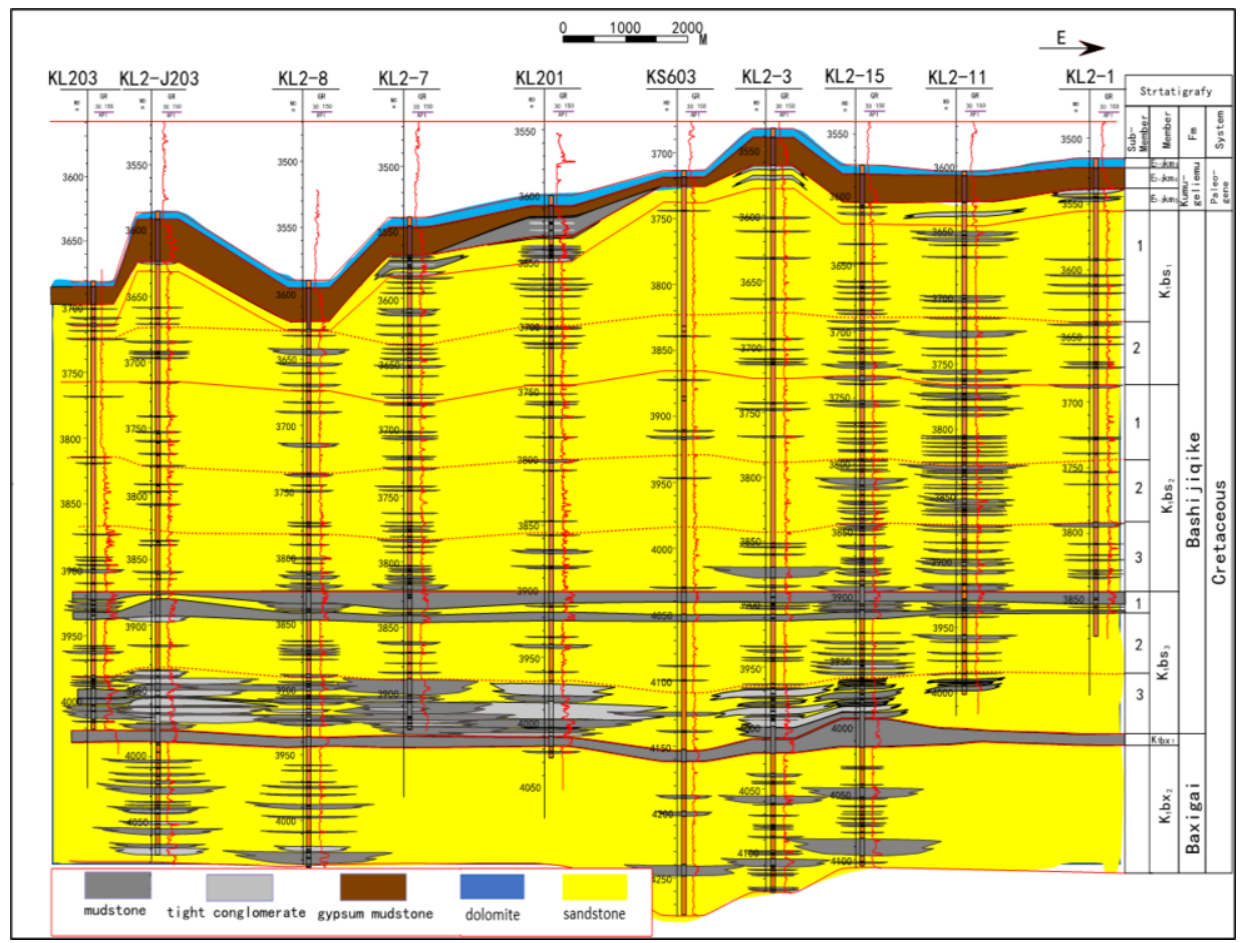

Figure 1. Sedimentary profile showing the reservoir distribution in Kela 2 gas field.
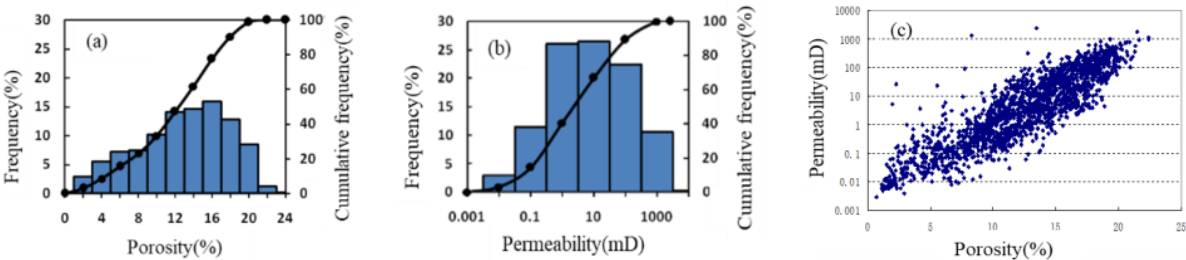

Figure 2. Distribution characteristics of porosity and permeability in Kela 2 gas field.

\section{Identification of High Permeability Zones}

In order to achieve quantitative identification of high permeability zone, the lower limit of high permeability must be determined. The lower limit is usually determined by the ratio of the defined zone permeability to the average permeability of the target formation, or of the low permeability zones within the formation $[6,11]$. In addition, Al-Dhafeeri and Nasr-El-Din introduced a method based on hight quality values of RQI and FZI [8]. In fact, high permeability is relative, so the lower limit should be different in different areas of gas field with plane heterogeneity. In order to better understand high permeability zone, this paper addressed a quick method of quantitatively identifying high permeability zone using the inflection point value of cumulative frequency curve of permeability distribution. 
Core experiments provide the most direct and intuitive data to evaluate reservoir permeability. However, because of the high cost and high process requirements, the drilling core is discontinuous in well and many wells do not carry out coring. At present, density logging (DEN) and acoustic logging (AC) are widely used to interpret wellbore porosity $(\varphi)$ and permeability $(k)$. In Kela 2 gas field, according to correlation analysis of core experimental data and logging geophysical characteristics, it is considered that density logging is the best choice to calculate reservoir physical properties. wellbore porosity $(\varphi)$ and permeability $(k)$ are calculated by equations (1) and (2).

$$
\begin{gathered}
\varphi=-0.41593 \times D E N+1.1588 \\
k=7.19 \frac{\varphi^{2.59}}{\mathrm{~S} w^{4.24}}
\end{gathered}
$$

Based on the interpretation results, the cumulative frequency distribution curves of permeability in 21 wells are analysed in detail. It can be seen that the great majority of samples are concentrated in the smaller permeability range on the left side of the curve inflection point, while a few samples are distributed in a large permeability range to the right of the point (figure 3). Therefore, the inflection point value can be considered to be the lower limit of high permeability zone. The lower limits of 21 wells are defined using this method. In single wells, the lower limit values vary from 20 to $180 \mathrm{mD}$, and they are 3-6 times of the permeability of the low permeability zones (figure 4). Then, the reservoir interval with permeability higher than the lower limit is defined as high permeability zone which is expected to be with high production.

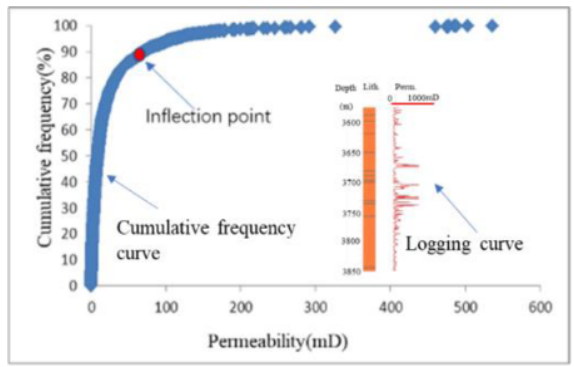

Figure 3. Cumulative frequency of permeability curve of well Kela 2.

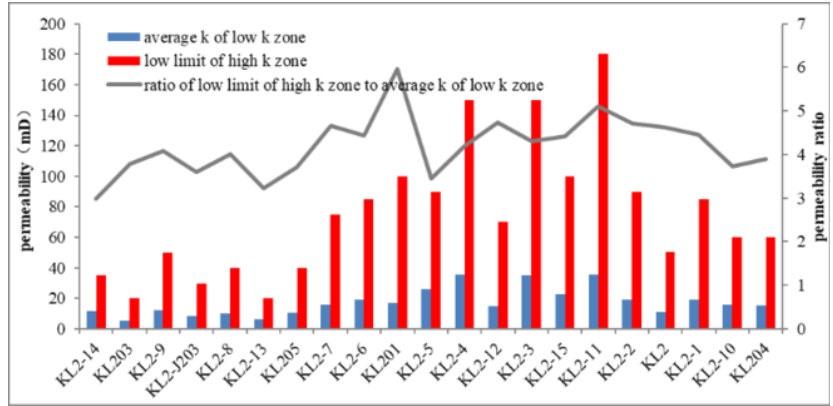

Figure 4. Lower limit of high permeability zones of single wells in Kela 2 gas field. 
Based on the discussion above, the high permeability zones of 21 wells are statistically analysed. These zones accounts for $10-15 \%$ of the total effective reservoir thickness in single wells (figure 5), and they are mainly distributed in the middle of the Bashijiqike $\left(\mathrm{K}_{1} b s\right)$ Formation (i.e., $\mathrm{K}_{1} b s_{1}{ }^{2}, \mathrm{~K}_{1} b s_{2}{ }^{1}$ and $\mathrm{K}_{1} b s_{2}{ }^{2}$; figure 6 show high permeability zone distribution in some wells).

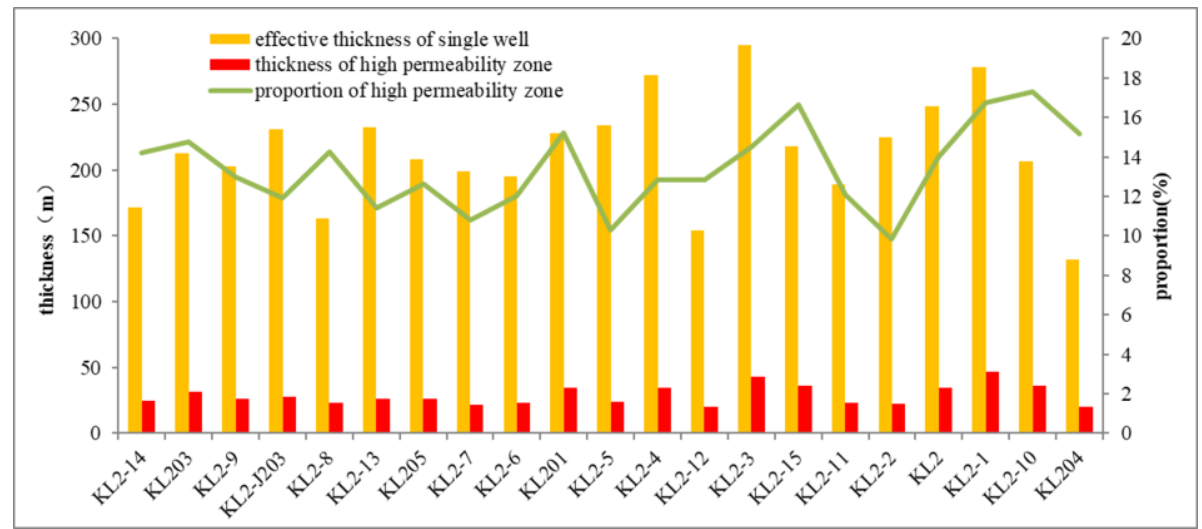

Figure 5. Comparison of high permeability zone thickness and effective thickness of single wells.
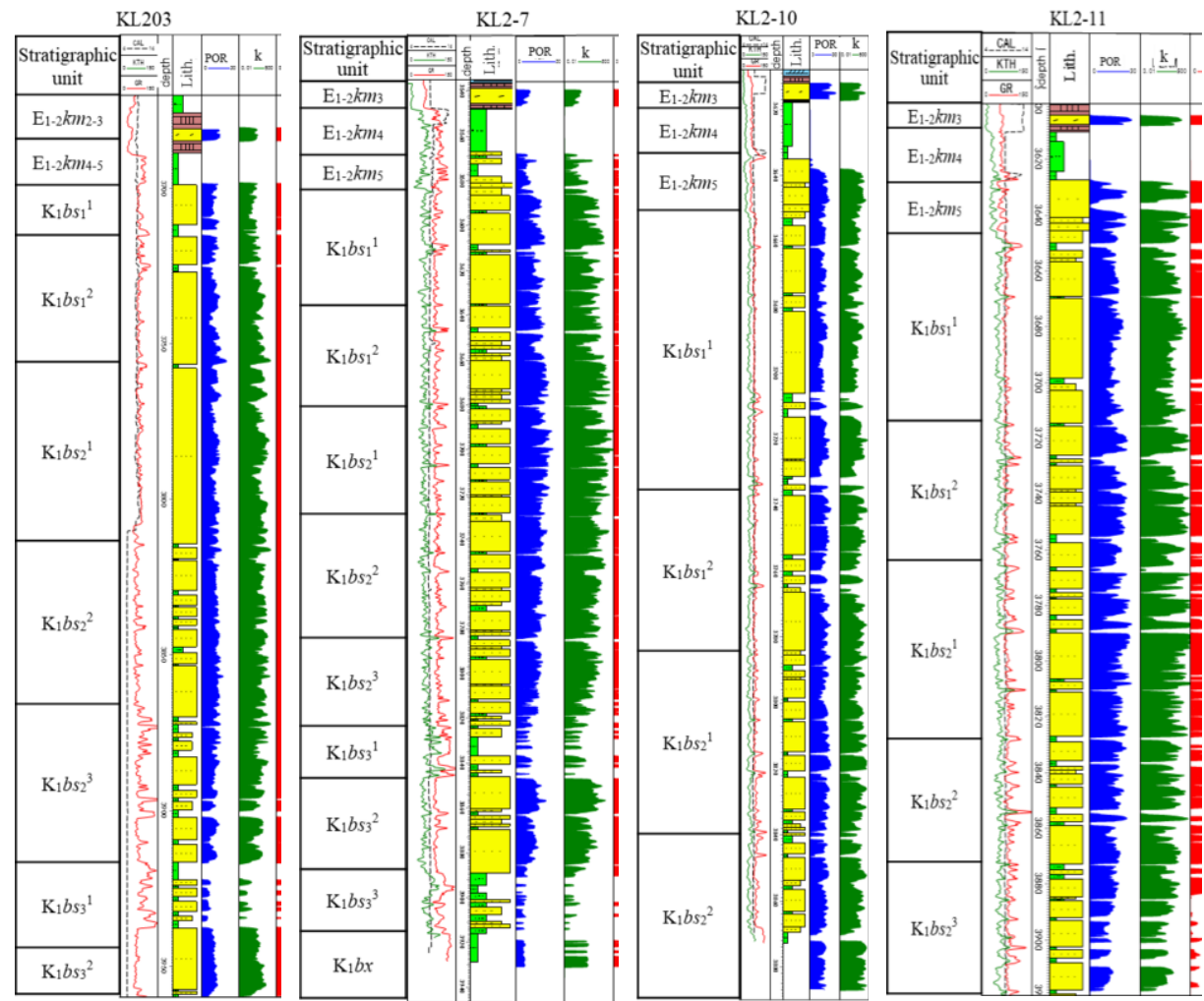

Figure 6. High permeability zone distribution in single wells (HkZ stand for high permeability zone). 


\section{Reservoir Behaviour}

Several researchers have studied the behaviour of multi-layer reservoirs without interlayer crossflow various perspectives [20-26]. It is found that when the multi-layer reservoirs with large permeability difference are commingled, the contribution rate of each layer to total production is different, and the layer with high permeability makes greater contribution than the layer with low permeability. How about the multi-layer reservoirs with interlayer crossflow? Kela 2 gas field provides an object for this study. According to the analysis of 1551 reservoir intervals from gas production profiles interpreted by production logging in Kela 2 gas field, it is found that 1098 intervals (account for $70.8 \%$ of the total intervals) have no contribution to the total production, thus the number of intervals with gas flow accounts for $29.2 \%$ of the total intervals (figure 7). A further analysis reveals that the numbers of intervals with relative gas production (The ratio of gas production of single test interval to that of all test intervals) more than $10 \%$ accounts for about $11 \%$ of the total intervals. The relative gas production of each interval is closely related to the permeability (figure 8). This means that the intervals that contribute a lot to the total production generally have high permeability. In most case, the effective gas producing interval is highly correlated with high permeability zone (figure 9). It can be found from figure 9 that in the early stage of gas well production, the high gas flow from the high permeability zones dominates the production profile, and in the late stage, water channelling occurs in the depth where the high permeability zones are located.

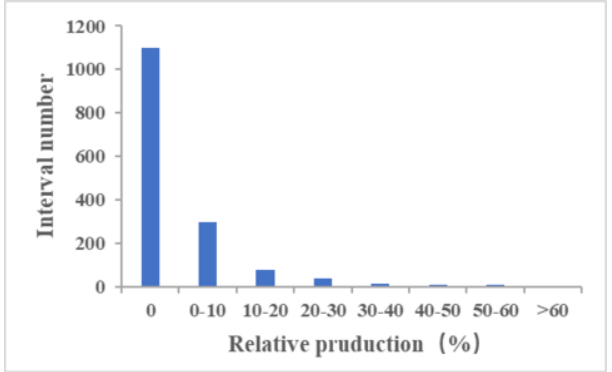

Figure 7. Statistical histogram of production intervals

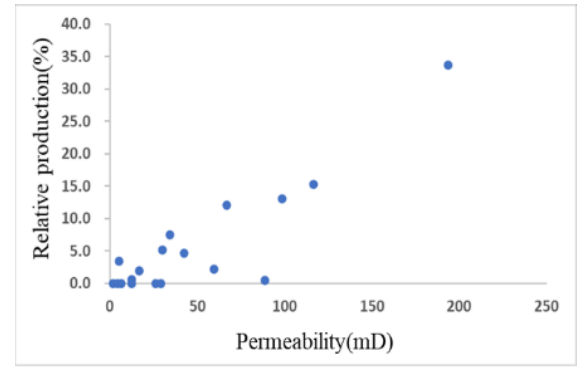

Figure 8. Relative production and of intervals with different permeability in a single well.

Since most of the low permeability zones have no gas flowing into the wellbore, can the reserves in these zones be produced? Geological analysis shows that the reserves of Kela 2 gas field are $2840 \times 10^{8} \mathrm{~m}^{3}$, of which the high permeability zone reserves are about $520 \times 10^{8} \mathrm{~m}^{3}$, and the cumulative gas production of the gas field has reached more than $1120 \times 10^{8} \mathrm{~m}^{3}$, which indicates that the low permeability zone reserves have been produced. Computer modelling of multi-layer reservoirs with interlayer crossflow shows that the pressure drop profile of each layer is quite different, and the pressure of high permeability layer decreases more rapidly than that of the low permeability layer [27]. Thus, the effective drainage radius of the high permeability layer is much larger than that of the low permeability layer. There is a pressure difference between high and low permeability zones. It has been proved that the reservoirs of Kela 2gas field are interconnected with each other and belong to a same pressure system [17-19]. As for Kela 2 gas field, it can be inferred that while gas flows laterally from the high 
permeability zones to the wellbore, gas flow occurs vertically from upper and lower zones to the central high permeability zones and horizontally through these zones to wellbore.

With the high-speed development of the field, the recovery degree of reserves in high permeability zones is much higher than that in low permeability zones. Therefore, the pressure of the high permeability zones is deficient, and the high permeability zones connecting the aquifer become the fast channels of formation water intrusion [28]. After the water intrudes into the gas reservoir, the gas/water two-phase flow occurs in the formation, which increases the gas flow resistance. As a result, the gas productivity of the water-producing well is dropped sharply, and the lifecycle of the well is shortened. KL 2-10 and KL 2-1 wells in the east of the gas field are typical examples associated with water channelling (figures 9 and 10). KL 2-10 well began to produce water associated with channelling in 2015. After 15 months, the water production reached $249 \mathrm{~m}^{3} / \mathrm{d}$, and the well was shut down due to failure to produce commercial gas flow. KL 2-1 well began to produce water in December 2018. After 13 months, the daily water production increased from $5 \mathrm{~m}^{3} / \mathrm{d}$ to $32 \mathrm{~m}^{3} / \mathrm{d}$, and the daily gas production decreased from $168 \times 10^{4} \mathrm{~m}^{3} / \mathrm{d}$ to $42 \times 10^{4} \mathrm{~m}^{3} / \mathrm{d}$. The water producing interval is $3696-3704 \mathrm{~m}$ in the middle of the borehole, which will affect the producing degree of reserves near the well.

\section{Efficient Development Countermeasures}

In the past 16 years since Kela 2 gas field was put into development, there have been 9 wells producing water, of which 5 wells are shut down due to failure to produce commercial gas flow, and the other 4 wells produce gas as well as water at the same time, resulting in a significant decline in gas productivity.

Inhomogeneous water invasion not only reduces gas well productivity and shortens gas well life, but also leads to water-sealed gas and reduces the ultimate gas recovery. Based on the study above, two key technical countermeasures are given to improve gas recovery: (1) In order to improve the production of reserves in low permeability zone and effectively restrain inhomogeneous water invasion associated with high permeability zones, horizontal wells should be deployed in the low permeability formation at the top of the first Member of the Bashijiqike Formation; (2) The effective drainage work of producing-water wells at the lower part of the structure should be carried out to delay channelling of the dynamic waterhead to the centre gas area. 


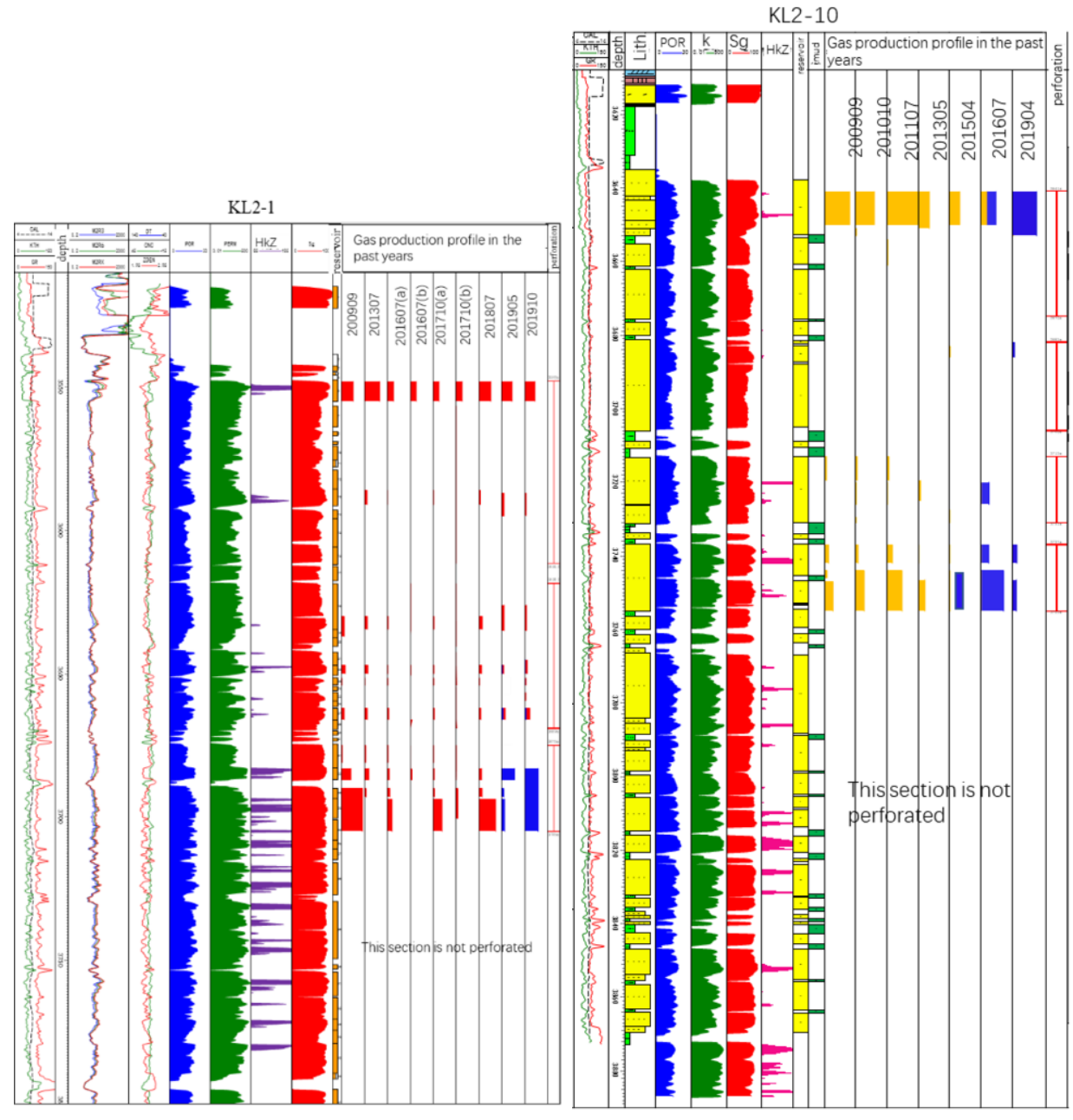

Figure 9. Gas production profiles of KL2-1and KL2-10 wells (HkZ stand for relative high permeability zone; in the gas production profile column, the red section and blue section show gas production and water production respectively).

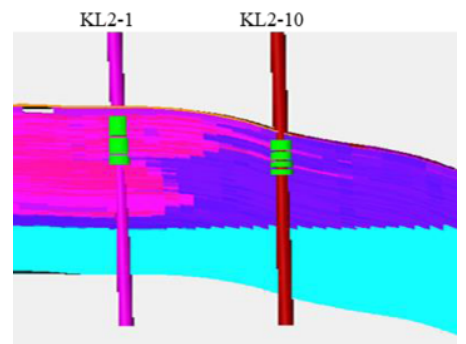

Figure 10. Water channelling phenomenon in Kela 2 gas field (by computer modelling). 


\section{Conclusion}

Kela 2 gas field has strong reservoir heterogeneity. High permeability zones in 21 wells in the field have been identified and characterized by conventional logging data and production profile analyses. This paper presents a method to define high permeability zone by using the inflection point of the cumulative frequency distribution curves of permeability. As a result, the high permeability zones are mainly distributed in the middle of the Bashijiqike $\left(\mathrm{K}_{1} b s\right)$ Formation (i.e., $\mathrm{K}_{1} b s_{1}{ }^{2}, \mathrm{~K}_{1} b s_{2}{ }^{1}$ and $\mathrm{K}_{1} b s_{2}{ }^{2}$ ). These high permeability zones are corresponding to the high yield intervals. They play the role of high velocity flow channels which drain overlying and underlying beds, and the gas in low permeability zones flows vertically to the high permeability zones and horizontally to wellbore through these zones. At the same time, the high permeability zones connecting the aquifer provide fast channels for the water migration. The presence of high permeability zones leads to early water breakthrough in some wells located in the east of the field, which affects the effective production of relatively low permeability reserves. In order to restrain the inhomogeneous water invasion and realize efficient development of the gas field, it is necessary to do a good job of perfecting well pattern and optimizing drainage scheme.

\section{References}

[1] Cumella S P, Shanley K W and Camp W K. 2008 The influence of stratigraphy and rock mechanics on Mesaverde gas distribution, Piceance Basin, Colorado AAPG Hedberg Series 3 137-155.

[2] Salman B, Robert H. Lander and Linda B 2002 Anomalously porosity and in deeply buried sandstone reservoirs: Origin and predictability AAPG Bulletin 86 (2) 301-328.

[3] Weber K J. 1982 Influence of common sedimentary structure on fluid flow in reservoir models Journal of Petroleum Technology 34 (3) 665-672.

[4] Qiu Y N and Chen Z Q 1996 Reservoir Description (Beijing: Petroleum Industry Press) p 344.

[5] Hu F T, et al. 1997 Development model of sandstone reservoir (Beijing: Petroleum Industry Press) p 267.

[6] Gao J, Ma D S and Yang S Y 2012 Quantitative identification of high permeability section in single sand body of low permeability reservoir Journal of China University of Petroleum (Edition of Natural Science) 36 (6) 13-18.

[7] Hemingway J, Doi M and Adani N 2001 Identification of high-permeability dolomitized zones using inelastic magnesium yield SPE Middle East Oil Show (Bahrain) SPE 68082 pp 17-20.

[8] Al-Dhafeeri A M and Nasr-El-Din H A 2007 Characteristics of high-permeability zones using core analysis and production logging data Journal of Petroleum Science and Engineering 55 18-36.

[9] Hui G, Zhang G L and Li F H 2011 Methods of identifying the relatively high permeability belt of reservoir combining study and production performance Science Technology and Engineering 7 (11) 4745-4749.

[10] Zou W and Wu X Q 2008 Recognition methods of high permeability zone in heterogeneous reservoir Xinjiang Geology 26 (3) 317-320.

[11] Cheng R H, Yao K, Huang Z T, et al. 2019 Distribution characteristics and significance of high permeability channel reservoir in Yaha gas condensate field 2019 International Field Exploration and Development Conference (Xi'an, China) IFEDC-20194131 pp 1-6.

[12] Amaefule J O, Altunbay M, Tiab D, et al. 1993. Enhanced reservoir description: Using core and log data to identify hydraulic (flow) units and predict permeability in uncored intervals/wells Annual Technical Conference and Exhibition (Houston, TX) SPE 26436 pp 3-6.

[13] Warren J E and Price H S 1961 Flow in heterogeneous porous media SPE Journal 1 (3) 153-169.

[14] Al-Dhamen A A, Pham T R and Al-Khatib M R 1998 A quick method of identifying and history matching a gravity dominated reservoir with localized super-permeabilities Annual Technical Conference and Exhibition (New Orleans, LA) SPE 49276 pp 27-30.

[15] Valle A, Pham A, Hsueh P T and Faulhaber J 1993 Development and use of a finely gridded window model for a reservoir containing super permeable channels SPE Middle East Oil Technical Conference and Exhibition (Bahrain) SPE 25631 pp 3-6. 
[16] Jia J H, Gu J Y, Guo Q Y, et al. 2001 Sedimentary facies of cretaceous reservoir in Kela 2 gas field of Tarim basin Journal of Palaeogeography 3 (3) 67-75.

[17] Jiang T W, Zhang H, Wang H Y, et al. 2017 Effects of faults geomechanical activity on water invasion in Kela 2 gas field, Tarim Basin Natural Gas Geoscience 28 (11) 1735-1744.

[18] Zhao L B, Dai J S, Sun Y, et al. 2012 Application of fractal geometry method to prediction of fractures in Kela 2 gas field of Tarim Basin Xingjiang Petroleum Geology 33 (5) 595-598.

[19] Wu Y P, Yang M, Sun Y, et al. 2019 Laws and models of water invasion in Kela 2 gas field Xingjiang Petroleum Geology 40 (6) 302-306.

[20] Hu Y, Zhu H Y, Chen J J, et al. 2007 Physical simulated study on the gas supplying mechanism of highlow permeable serial-connection-formation Natural Gas Geoscience 18 (3) 469-472.

[21] Zhu H Y, Hu Y, Li J T, et al. 2013 Physical simulation of commingled production for multilayer gas reservoir in Sebei gas field, Qaidam Basin Acta Petrlie Sinica 34 (Sl) 136-142.

[22] $\mathrm{Hu}$ Y, Li X, Wan Y, et al. 2009 Gas production property of commingled production for high- low pressure double gas reservoir Natural Gas Industry 29 (2) 89-91.

[23] Xiong Y, Zhang L H, Yang F Y, et al. 2005 Study on the technical policy and threshold value of multiplezone production with one well for multi-layered gas reservoir Natural Gas Industry 25 (7) 81-83.

[24] Kucuk F, Karakas M and Ayestaran L 1986 well testing and analysis techniques for layered reservoirs SPE Form. Eval. 1 (4) 324-354.

[25] Fetkovich M J, Bradley M D and Works A M 1990 Depletion performance of layered reservoirs without crossflow SPE Form. Eval. 5 (3) 310-318.

[26] Wang M X, Fan Z F, Luo W J, et al. 2017 Production performance of multi-layer unconsolidated sandstone gas reservoirs under influence of multiple factors: A case study of S gas field Journal of Xi'an Shiyou University (Natural Science Edition) 32 (6) 79-86.

[27] Byrnes A P 2005 Permeability, capillary pressure, and relative permeability properties in lowpermeability reservoirs and the influence of thin, high-permeability beds on production Gas in Low Permeability Reservoirs of the Rocky Mountain Region ed Bishop M G, Cumella S P, Robinson J W and Silverman M R (Rocky Mountain Association of Geologists 2005 Guidebook CD) pp 69-108.

[28] He X D, Zou S L and Lu X M 2006 A preliminary discussion on mechanism of water invasion characteristics in edge water drive gas reservoirs Natural Gas Industry 26 (3) 87-89. 